University of Wollongong

Research Online

Faculty of Engineering - Papers (Archive)

Faculty of Engineering and Information

Sciences

2009

\title{
Butterfly wings as natural photonic crystal scaffolds for controllable assembly of CdS nanoparticles
}

Jie Han

Shanghai Jiaotong University

Huilan Su

Shanghai Jiaotong University

Di Zhang

Shanghai Jiaotong University

Jianjun Chen

Shanghai Jiaotong University

Z. Chen

University of Wollongong, zchen@uow.edu.au

Follow this and additional works at: https://ro.uow.edu.au/engpapers

Part of the Engineering Commons

https://ro.uow.edu.au/engpapers/5459

\section{Recommended Citation}

Han, Jie; Su, Huilan; Zhang, Di; Chen, Jianjun; and Chen, Z.: Butterfly wings as natural photonic crystal scaffolds for controllable assembly of CdS nanoparticles 2009.

https://ro.uow.edu.au/engpapers/5459

Research Online is the open access institutional repository for the University of Wollongong. For further information contact the UOW Library: research-pubs@uow.edu.au 


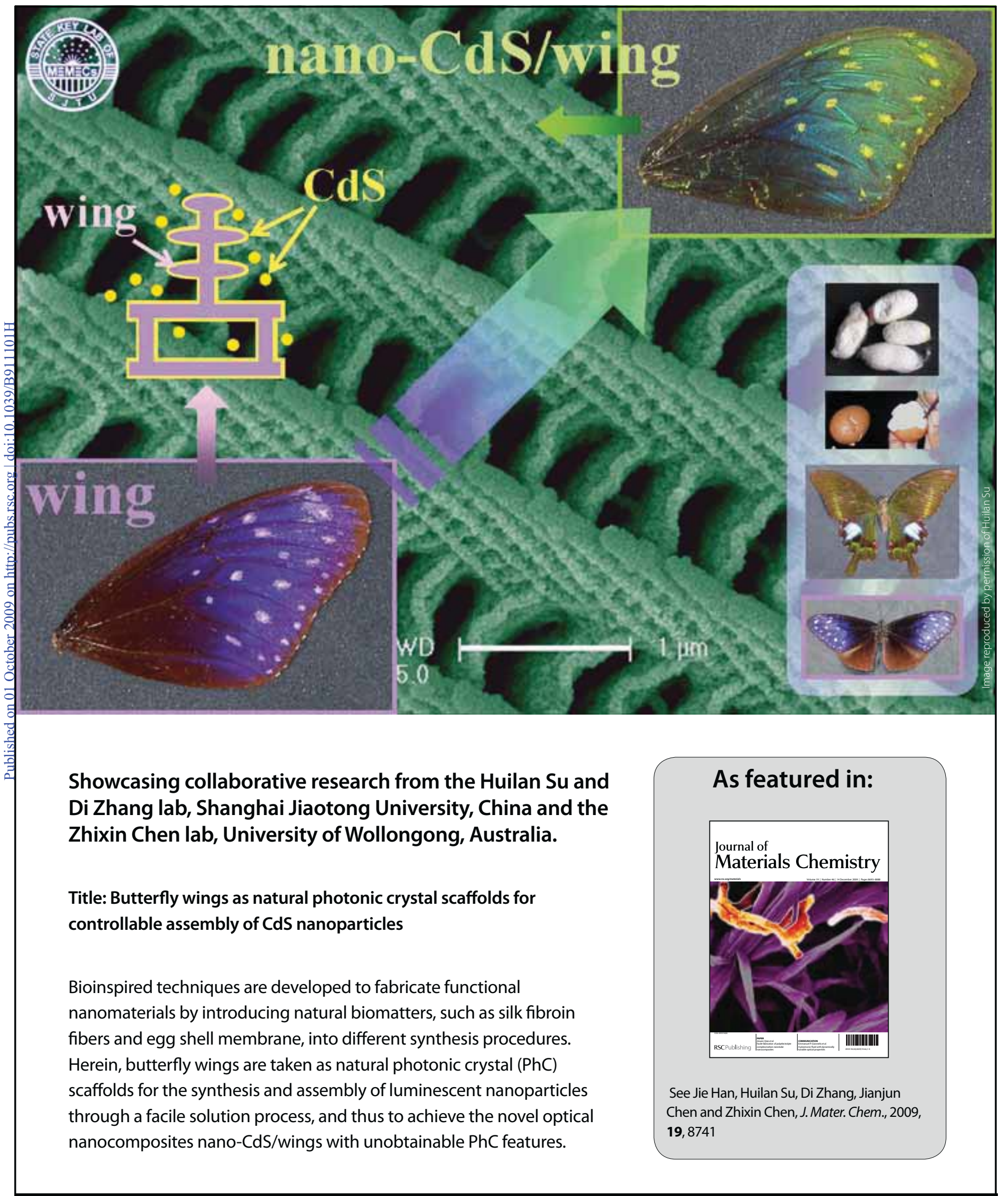

RSCPublishing

www.rsc.org/materials 


\title{
Butterfly wings as natural photonic crystal scaffolds for controllable assembly of CdS nanoparticles $\dagger$
}

\author{
Jie Han, ${ }^{a}$ Huilan Su, ${ }^{* a}$ Di Zhang, ${ }^{* a}$ Jianjun Chen ${ }^{a}$ and Zhixin Chen ${ }^{b}$ \\ Received 8th June 2009, Accepted 9th September 2009 \\ First published as an Advance Article on the web 1st October 2009 \\ DOI: 10.1039/b911101h
}

\begin{abstract}
A facile solution process is developed, through which butterfly wings are taken as natural photonic crystal $(\mathrm{PhC})$ scaffolds to control the synthesis and assembly of CdS nanocrystallites, and thus to achieve novel optical nanocomposites with unobtainable PhC features. Practically, the original wings can be activated by an EDTA/DMF suspension to first serve as in-situ reactive substrates for $\mathrm{CdS}$ seeds, and then provide the $\mathrm{PhC}$ structures for the following heterogeneous deposition of $\mathrm{CdS}$ nanoparticles (nano-CdS). The obtained nano-CdS covering precisely preserves the efficient structure details of the natural PhCs from macro-scale down to $\sim 100 \mathrm{~nm}$. In the resulting nano-CdS/butterfly wing composites, the assembly patterns of nano-CdS can be controlled at two levels: one is the $\mathrm{PhC}$ structures $(>100 \mathrm{~nm})$ decided by the wing scale hierarchy, the other is the nano-CdS small clusters $(<100 \mathrm{~nm})$ distributed on the PhC structures. Such a combination of nano-CdS and butterfly wings should create novel optoelectronic properties, and relevant ideas could inspire the investigation of $\mathrm{PhC}$ materials.
\end{abstract}

\section{Introduction}

Recently, the controlled assembly of light emitting nanoparticles by photonic crystal $(\mathrm{PhC})$ structures has stimulated great attention in materials science. The optical properties of such assemblies are supposed to be tuned not only by nanoparticle intrinsic characteristics like size, shape and surface, but also by PhC structures, which would be of great importance in future nanoscaled light sources. ${ }^{1}$ Among light emitting species, $\mathrm{CdS}$ is quite suitable in both $\mathrm{PhCs}$ and some optical devices, for its high refractive index (ranges from 2.3 to 2.5 for wavelength between 800 and $400 \mathrm{~nm})^{2}$ and visible photoluminescence (direct bandgap near $2.4 \mathrm{eV}$ for bulk material), ${ }^{3}$ respectively. $\mathrm{CdS}$ nanoparticles (nano-CdS) have been periodically assembled by templating artificial $\mathrm{PhCs}$, and successfully perform highly tunable spontaneous emission. ${ }^{4}$ However, the available artificial $\mathrm{PhC}$ structures that can be used to assemble nanoparticles either lack pattern variety, or require super-expensive apparatus, ${ }^{5}$ which becomes an obstacle to highly controllable optical devices. So it is of great importance to explore more applicable $\mathrm{PhC}$ structures for the assembly of light emitting nanoparticles.

Besides artificial $\mathrm{PhCs}$, nature has created quite a lot $\mathrm{PhCs}$ with abundant structure patterns. ${ }^{6}$ It is proposed that natural $\mathrm{PhCs}$ could also be introduced to mediate the assembly of nano-CdS, and might be potential substitutes for pattern-limited artificial

\footnotetext{
${ }^{a}$ State Key Lab of Metal Matrix Composites, Shanghai Jiaotong University, Shanghai, China. E-mail: hlsu@sjtu.edu.cn; zhangdi@sjtu. edu.cn; Fax: +862134202749; Tel: +862134202584

${ }^{b}$ Engineering Materials Institute, Faculty of Engineering, University of Wollongong, Wollongong, NSW 2522, Australia

$\uparrow$ Electronic supplementary information (ESI) available: The evolution of $1728 \mathrm{~cm}^{-1}$ band and $1415 \mathrm{~cm}^{-1}$ band in FTIR spectra as well as the FESEM images of the sample prepared with only Step II. See DOI: $10.1039 / \mathrm{b} 911101 \mathrm{~h}$
}

PhCs. Such a notion should be feasible, considering that micro-/nano-scale biostructures usually have active surfaces ${ }^{7}$ and have already been applied in the fabrication of various functional nanomaterials. ${ }^{8}$ In fact, spider silk fibrous structures have been used as active templates to load gold nanoparticles for vapor sensing. ${ }^{9}$ Sea urchin skeleton plate, ${ }^{10}$ cuttlebone-derived organic matrix, ${ }^{11}$ bacteria ${ }^{12}$ and pollen ${ }^{13}$ have been involved in the fabrication of inorganic macroporous structures, which might have applications in separation and drug delivery. In addition, eggshell membrane, ${ }^{14}$ swim bladder membrane, ${ }^{15}$ wood ${ }^{16}$ and cellulose,${ }^{17}$ which contain natural hierarchical structures, have been replicated by oxide functional materials, for the sake of achieving outstanding catalytic, gas-sensing and photovoltaic properties. Thus, useful natural PhCs with both active surfaces and unusual subtle structures might also exist in nature, and should be superior to artificial substrates in assembling inorganic nanoparticles for advanced nanocomposites with excellent optical performance. ${ }^{18}$

Among various natural PhCs, butterfly wing scales have attracted great research interest. As we know, the wing scales of some butterfly species contain $\mathrm{PhC}$ structures composed of periodically arranged air and protein/chitin hybrids with subtle structures and diverse patterns. ${ }^{19,20}$ It is noteworthy that they have already been used as $\mathrm{PhC}$ templates in materials fabrication. In 2003, Cook et al. achieved silica replication of butterfly wings by chemical vapor deposition. ${ }^{21}$ Subsequently, ferroelectric inverse replication, ${ }^{22} \mathrm{Al}_{2} \mathrm{O}_{3}$ hollow replication, ${ }^{23}$ phosphor replication ${ }^{24}$ and $\mathrm{TiO}_{2}$ exact replication ${ }^{25}$ of butterfly wings were accomplished by a sol-gel process, atomic layer deposition, solution casting and a dipping process, respectively. Since PhCs could participate in tuning nano-CdS spontaneous emission, ${ }^{26}$ the combination of nano-CdS (photoluminescence species) and wing scales (natural $\mathrm{PhCs}$ ) would be promising and significant.

Herein, two species of butterflies with different wing scale patterns are taken as novel reactive $\mathrm{PhC}$ scaffolds for 
nanoparticle assembly. Practically, original wings are activated via an EDTA/DMF treatment, then involved in the in situ synthesis of $\mathrm{CdS}$ seeds, followed by a solvothermal process (Fig. 1). The influence of the procedure factors on the patterns of nano-CdS/wings is also investigated extensively. It is hoped that wing scales (natural $\mathrm{PhCs}$ ) could be the substitutes for artificial $\mathrm{PhCs}$ in assembling nanoparticles, and this research would broaden the pattern diversity of nano-CdS/PhCs for novel optical materials.

\section{Experimental}

Butterflies Euploea mulciber (subfamily Danainae of the family Danaidae) and Papilio paris (subfamily Papilioninae of the family Papilionidae) were purchased from a butterfly garden in Shanghai. The $\mathrm{Cd}^{2+}$ impregnant was prepared by dissolving $0.4 \mathrm{~g}$ $\mathrm{CdCl}_{2} \cdot 2.5 \mathrm{H}_{2} \mathrm{O}$ in a mixture of $5 \mathrm{ml}$ ethanol and $4 \mathrm{ml}$ ammonia (pH: 9.7), while the $\mathrm{S}^{2-}$ impregnant was prepared by dissolving $0.18 \mathrm{~g} \mathrm{Na} 2 \mathrm{~S} \cdot 9 \mathrm{H}_{2} \mathrm{O}$ in $60 \mathrm{ml}$ ethanol. To facilitate the in situ reaction on natural wings, an activation medium (suspension) was prepared by dispersing ethylenediaminetetraacetic acid (EDTA) in dimethylformamide (DMF) with a volume ratio of about 1:10.

For a typical procedure (Fig. 1), the original butterfly wing was openly immersed in the above activation medium at $110^{\circ} \mathrm{C}$ for $6 \mathrm{~h}$ to obtain the EDTA/DMF activated wing. The activated wing was soaked in $\mathrm{Cd}^{2+}$ impregnant at $60{ }^{\circ} \mathrm{C}$ for 30 min, taken out and rinsed thoroughly, and then soaked in $\mathrm{S}^{2-}$ impregnant at room temperature (RT) for $30 \mathrm{~min}$, again taken out and rinsed thoroughly. This procedure was adopted to obtain CdS seeds for the subsequent process, and is named as Step I. Step II was carried out as follows: the CdS seeds/wing was put into the $\mathrm{Cd}^{2+}$ impregnant again, followed by the addition of thiourea $(0.115-0.2 \mathrm{~g})$, then the system was placed in an autoclave and kept at $100{ }^{\circ} \mathrm{C}$ for $30-40 \mathrm{~min}$. Finally, the treated wing was taken out and rinsed thoroughly to harvest the target sample $\mathrm{CdS} /$ wing. The procedure factors were adjusted to obtain different patterns of CdS small clusters (Table 1).

FTIR measurements were recorded using a Bruker EQUINOX 55 instrument with samples mashed to powder and

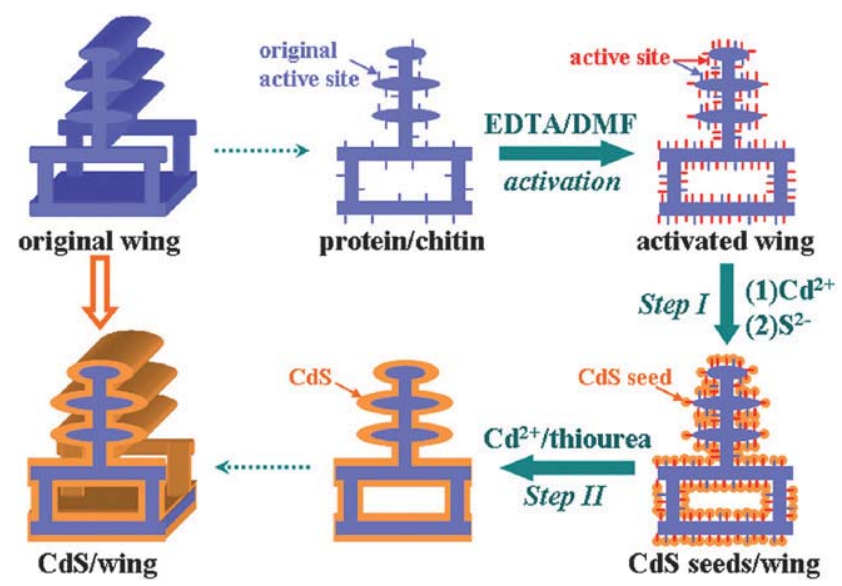

Fig. 1 Illustration depicting the activation of original butterfly wings and the formation of CdS coating on the activated wing scaffold. 
compressed into $\mathrm{KBr}$ pellets. XRD measurements were carried out on a D/max-2550/PC instrument. Reflection spectra were measured on a CRAIC QDI 2010 superior microspectrophotometer. FESEM images were investigated on an FEI Sirion 200 field emission gun scanning electron microscope operated at an acceleration voltage of $5.0 \mathrm{kV}$. TEM/HRTEM measurements were taken on a JEOL-2011F transmission electron microscope under an acceleration voltage of $200 \mathrm{kV}$, with samples shaken into fragments in ethanol by ultrasonic agitation. Bright field images, energy dispersive X-ray spectra (EDX) and selected area electron diffraction (SAED) patterns were examined.

\section{Results and discussion}

Original butterfly wings are constituted by protein and chitin. ${ }^{20}$ As indicated in Fig. 2, the absorption bands at 1655 and $1543 \mathrm{~cm}^{-1}$ are the signals of amide I and amide II for protein structure, respectively. The bands at 1157, 1115, 1074 and $1030 \mathrm{~cm}^{-1}$ should be assigned to the vibrational motion of characteristic $\mathrm{C}-\mathrm{O}$ bonds of chitin. The $1728 \mathrm{~cm}^{-1}$ band $(\mathrm{C}=\mathrm{O}$ stretching from $\mathrm{COOH}$ ) corresponds to the $\mathrm{COOH}$ of aspartic and glutamic acid residues, ${ }^{27}$ and the $1250 \mathrm{~cm}^{-1}$ band is attributed to $\mathrm{S}=\mathrm{O}$ stretching vibration. Although there are some original active sites (like $-\mathrm{COOH}$ and $-\mathrm{OH}$ ) on butterfly wings that derived from the protein/chitin components, the activation of wings is essential to obtain ideal scaffolds with sufficient active sites. As depicted in Fig. 1, the original wing is treated with EDTA/DMF activation medium to gain additional $\mathrm{COO}^{-}$active sites, resulting in the slight intensification of the $1415 \mathrm{~cm}^{-1}$ band $\left(\mathrm{COO}^{-}\right.$stretching) in the FTIR spectrum. Then the activated wing is taken as the reactive scaffold to bind $\mathrm{Cd}^{2+}$, and in succession attract $\mathrm{S}^{2-}$ to in situ formed CdS seeds (Step I), which is confirmed by the FTIR results. In detail, the $1728 \mathrm{~cm}^{-1}$ band $(\mathrm{COOH})$ disappears, along with the enhancement of the $1415 \mathrm{~cm}^{-1}\left(\mathrm{COO}^{-}\right)$and $1115 \mathrm{~cm}^{-1}$ bands $(\mathrm{C}-\mathrm{O}$ stretching from ring $\mathrm{C}-\mathrm{OH}$ ), owing to the binding of $\mathrm{Cd}^{2+}$. So the active sites in

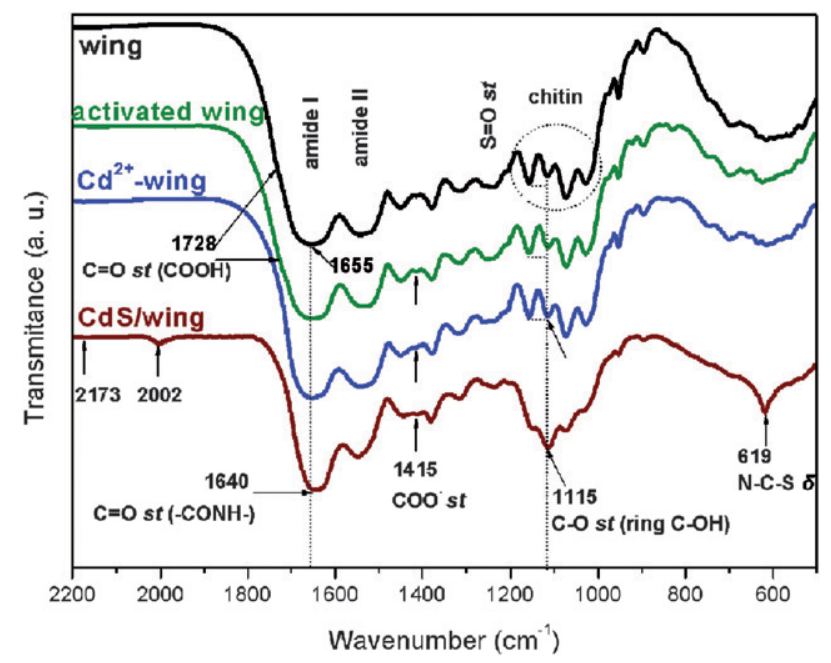

Fig. 2 FTIR spectra of the original wing, the activated wing, the $\mathrm{Cd}^{2+}$ wing and the product $\mathrm{CdS} /$ wing. $\mathrm{Cd}^{2+}$-wing represents the reaction intermediate in Step I that was obtained by immersing the activated wing in $\mathrm{Cd}^{2+}$ impregnant. The evolution of the $1728 \mathrm{~cm}^{-1}$ and $1415 \mathrm{~cm}^{-1}$ bands is described in the ESI. $\dagger$
Step I should include the $\mathrm{COOH} / \mathrm{COO}^{-}$groups of wing protein $\left(\mathrm{COO} \cdots \mathrm{Cd}^{2+}\right),{ }^{28}$ the ring $\mathrm{C}-\mathrm{OH}$ groups of wing chitin (ring $\left.\mathrm{C}-\mathrm{O} \cdots \mathrm{Cd}^{2+}\right),{ }^{29}$ as well as the additional $\mathrm{COO}^{-}$groups $(\mathrm{COO} \cdots$ $\mathrm{Cd}^{2+}$ ) from the previous activation agent EDTA (supported by subsequent FESEM observation). Thereafter, the CdS seeds/ wing is transferred into a solvothermal system containing $\mathrm{Cd}^{2+}$ (accurately $\left[\mathrm{Cd}\left(\mathrm{NH}_{3}\right)_{4}\right]^{2+}$ ) and thiourea, where thiourea is supposed to decompose and supply $\mathrm{S}^{2-}$ for the heterogeneous CdS deposition on the CdS seeds/wing scaffold (Step II): ${ }^{30}$

$$
\begin{gathered}
\left(\mathrm{NH}_{2}\right)_{2} \mathrm{CS}+\mathrm{OH}^{-} \rightarrow \mathrm{NCNH}_{2}+\mathrm{SH}^{-}+\mathrm{H}_{2} \mathrm{O} \\
\mathrm{NCNH}_{2}+\mathrm{H}_{2} \mathrm{O} \rightarrow \mathrm{O}=\mathrm{C}\left(\mathrm{NH}_{2}\right)_{2} \rightarrow \mathrm{NH}_{4} \mathrm{CNO} \\
\mathrm{SH}^{-}+\mathrm{OH}^{-} \rightarrow \mathrm{S}^{2-}+\mathrm{H}_{2} \mathrm{O}
\end{gathered}
$$

Along with the further deposition of CdS on the scaffold (Step II), the $1415 \mathrm{~cm}^{-1}$ band $\left(\mathrm{COO}^{-}\right.$) and the $1115 \mathrm{~cm}^{-1}$ band (ring $\mathrm{C}_{-}$ $\mathrm{OH}$ ) are again intensified and the $1655 \mathrm{~cm}^{-1}$ band (amide $\mathrm{I}: \mathrm{C}=\mathrm{O}$ stretching from $-\mathrm{CONH}-)$ shifts to $1640 \mathrm{~cm}^{-1}\left(\mathrm{C}=\mathrm{O} \cdots \mathrm{Cd}^{2+}\right)$ with higher intensity. Therefore, not only the previously mentioned $\mathrm{COO}^{-}$and ring $\mathrm{C}-\mathrm{OH}$, but also $\mathrm{C}=\mathrm{O}$ on peptide bonds are involved in the synthesis and assembly. It should also be mentioned that the minor band at $2173 \mathrm{~cm}^{-1}$ in the FTIR spectrum of the final product $\mathrm{CdS} /$ wing is due to the small amount of the remnant byproduct $(\mathrm{N}=\mathrm{C}=\mathrm{O})^{-}$, which supports reaction (2). Besides, the additional band at $2002 \mathrm{~cm}^{-1}$ $\left((\mathrm{N}=\mathrm{C}=\mathrm{S})^{-}\right.$from the coexisting impurity of thiourea) suggests the existence of thiourea, while that at $619 \mathrm{~cm}^{-1}(\mathrm{~N}-\mathrm{C}-\mathrm{S}$ asymmetric bending of thiourea- $\left.\mathrm{Cd}^{2+}\right)^{31}$ indicates the chelation between thiourea and CdS in the final product. Accordingly, butterfly wings could be activated by EDTA/DMF suspension to serve as reactive scaffolds for the in situ formation and successive assembly of CdS, and the obtained CdS covering is bonded by thiourea.

The loading of CdS on butterfly wings is also evidenced by both naked-eye and XRD measurements as shown in Fig. 3. The original forewing of male butterfly Euploea mulciber exhibits a shining violet color, which should correspond to its $\mathrm{PhC}$ structure (supported by the reflection spectrum). ${ }^{32}$ After

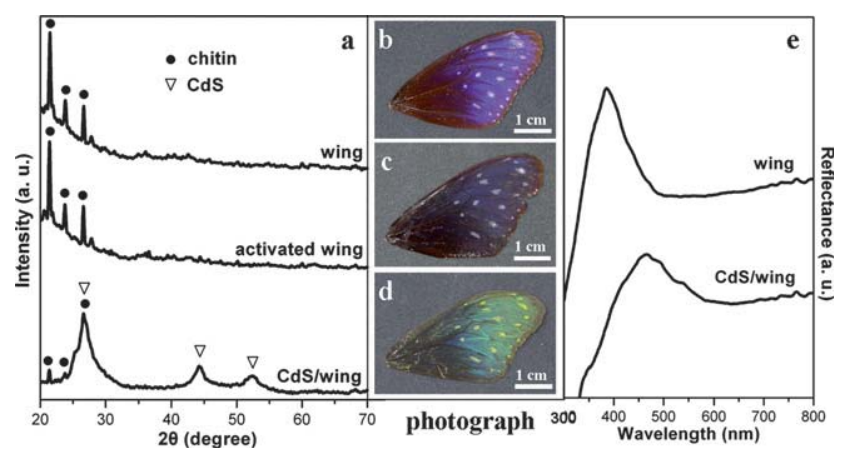

Fig. 3 (a) XRD patterns of the original wing, the activated wing and the final product $\mathrm{CdS} /$ wing. Photographs of (b) the original wing, (c) the activated wing and (d) the final product CdS/wing. (e) Reflection spectra of the original wing and the final product $\mathrm{CdS} /$ wing at normal incidence. (The forewing of male Euploea mulciber butterflies was used). 
activation, the wing turns to purplish blue with lower brightness and color saturation. This should be ascribed to the change of $\mathrm{PhC}$ parameters (e.g. refractive index and lattice distance) during the activation process, and the colored phenomenon implies that the $\mathrm{PhC}$ structure might still be present. ${ }^{32}$ In addition, there appear three similar main peaks at $21.5^{\circ}, 23.8^{\circ}$ and $26.7^{\circ}$ on the respective XRD patterns of the original wing and the activated wing, indicating they have the same components. The $21.5^{\circ}$ and $23.8^{\circ}$ peaks also appear in the final product, so the chemical components of the original wing are considered to be almost intact during the whole loading process. Besides, the additional broadened peaks at $26.6^{\circ}, 44.2^{\circ}$ and $52.3^{\circ}$ in the XRD pattern of the final product $\mathrm{CdS} /$ wing demonstrate the formation of $\mathrm{CdS}$ crystallites on the wing, and the broadening is a hint that asformed CdS might be small-sized crystallites. It should be mentioned that the peak at $26.6^{\circ}$ is a combination peak of chitin $\left(26.7^{\circ}\right)$ and $\mathrm{CdS}$ at this range. Due to the successful CdS loading, the final product $\mathrm{CdS} /$ wing displays a shining greenish blue color that correlates to the reflection peak centered on $465 \mathrm{~nm}$. The reflection peak should imply the existence of a photonic bandgap, thus the color should be considered as $\mathrm{PhC}$ structural color. Considering the differences between the reflection spectra of the original wing and the $\mathrm{CdS} /$ wing, it is suggested that the wing's $\mathrm{PhC}$ structure is inherited but the $\mathrm{PhC}$ parameters (e.g. refractive index and lattice distance) are changed by the loaded CdS. Therefore, CdS crystallites could be loaded on activated butterfly wings without destroying the $\mathrm{PhC}$ structures, which is supported by the reflection spectra and can be further demonstrated by FESEM measurement as follows.

Owing to the CdS coating, the surface of the final product is slightly rougher than that of the original wing by FESEM observation under high magnification (Fig. 4a). However, the coating is so homogeneous that the subtle structure of the original wing is precisely covered from micrometer down to $\sim 100 \mathrm{~nm}$. Not only the microscaled parallel ridges (Fig. $4 \mathrm{~b}$ ), but also the nanoscaled overlapping layers within the ridges (Fig. 4a)

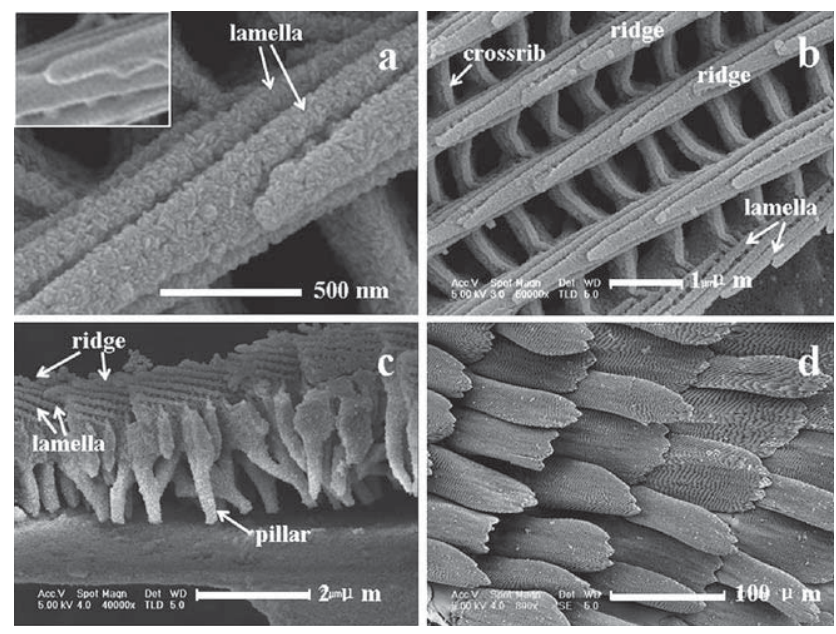

Fig. 4 FESEM images of the final product CdS/wing obtained by the typical procedure as described in the experimental section. Inset in (a) shows the FESEM image of the original wing under corresponding magnification for comparison. (The forewing of male Euploea mulciber butterflies was used). are preserved and clearly revealed in the final product $\mathrm{CdS} /$ wing. These structures are essential to the $\mathrm{PhCs}$ of original wing, ${ }^{32}$ so it can be concluded that the efficient structure details of the natural $\mathrm{PhCs}$ could be maintained. Besides, the pillars structure beneath the ridges is also covered with the smooth $\mathrm{CdS}$ layer as revealed in the image of the cross-sectioned wing scale (Fig. 4c), indicating the uniform CdS coating of the interior structure. Under low magnification (Fig. 4d), the final product presents similar arrays of scales as the original wing. Thus, CdS nanocrystallites are distributed homogeneously on both the exterior and the interior surfaces of wing scaffolds from nano-scale up to macro-scale, having the ability to precisely coat the natural $\mathrm{PhC}$ scaffolds and finally achieve promising hybrid nanocomposites.

Details of the CdS coating could be studied by TEM analyses (Fig. 5). To prepare the TEM sample, the final product CdS/wing was shaken into fragments in ethanol by ultrasonic agitation. $\mathrm{Cd}$, $\mathrm{S}$ and $\mathrm{C}$ elements were detected using an EDX accessory, corresponding to the $\mathrm{CdS}$ coating and the protein/chitin components of the original wing. It is noteworthy that the existence of $\mathrm{CdS}$ in the fragments should be due to the chemical bonding between CdS and wing, as revealed by the previously mentioned FTIR results. The HRTEM image shows the building blocks of the CdS layer to be CdS nanocrystallites with diameters of 6-7 nm, which is coincident with the broadened peaks of the XRD patterns. The SAED image displays ring and dot (Fig. 5c) patterns, relating to the major and minor phases in the product, respectively. The clear rings match well with the cubic CdS phase reported in JCPDS card No. 89-0440, and the relevant planes could be indexed as (111), (220), (311), (331) and (422), respectively. In addition, the weak dots could be indexed as (102) and (103) planes of the hexagonal CdS phase. The lattice fringes (d-spacing: $0.338 \mathrm{~nm}$ ) of the single nanoparticle in the HRTEM image should be considered as the (111) reflection of the cubic $\mathrm{CdS}$ phase. Therefore, the as-prepared CdS coating is mainly constructed by cubic $\mathrm{CdS}$ nanocrystallites with diameters of 6-7 nm, and contains only a small amount of hexagonal CdS.

It is well known that the patterns of nano-CdS/PhCs are essential to their optical properties. Herein, several types of wing scales with different patterns are applied to mediate the assembly of nano-CdS. Fig. 6a presents the side view of the parallel ridges on a scale of CdS/wing that based on the colored wing of the male

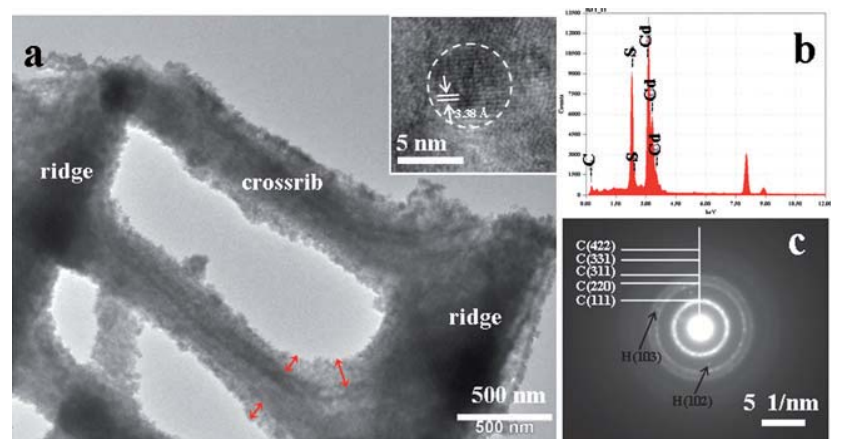

Fig. 5 (a) TEM image, (b) EDX results and (c) SAED pattern of the final product $\mathrm{CdS} /$ wing obtained by the typical procedure as described in the experimental section. Inset in (a) displays the HRTEM image of a single CdS nanoparticle. (The forewing of male Euploea mulciber butterflies was used). 

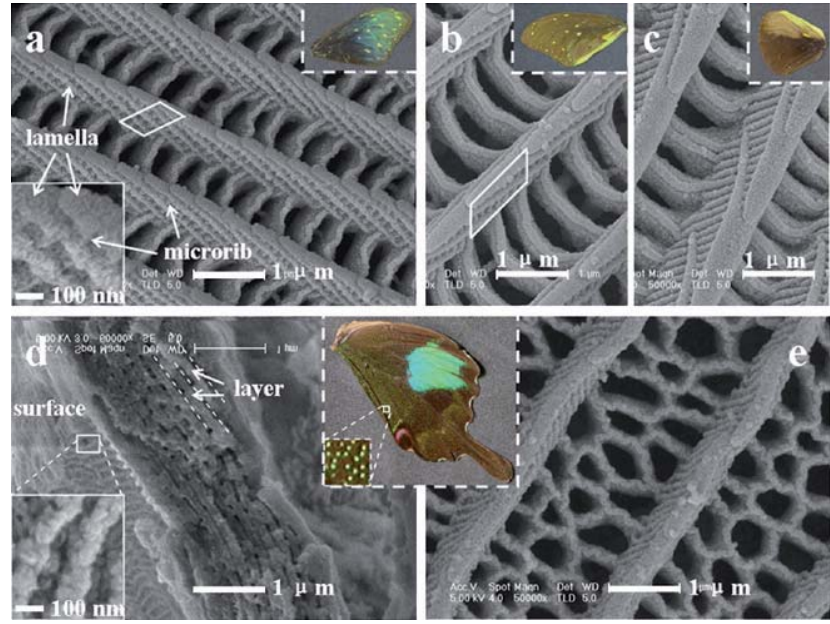

Fig. 6 FESEM images of the nano-CdS/wings, corresponding to (a-c) male Euploea mulciber butterflies and (d,e) Papilio paris butterflies; (d) shows a cross-section image. The upper-right insets of $(\mathrm{a}-\mathrm{c})$ and the inset between (d) and (e) display correlating photographs of nano-CdS/wings. The higher magnification images of (a) and (d) are shown as lower-left insets, revealing their surface details. Parallelograms in (a) and (b) are drawn for the determination of the number of lamella periods of one ridge, considering that the microribs are perpendicular to the lamellas.

Euploea mulciber butterfly. It is clear that the overlapping lamellas within the ridges are slightly tilted from the scale surface, parallel to each other, and connected by the microribs that are perpendicular to the lamellas. ${ }^{33}$ The number of lamella periods of one ridge could be determined by a parallelogram that has two sides tracing the microribs as shown in Fig. 6a, and is considered to be four. Herein, the ridge-lamella structure is essential to the PhC colors of the original wing and the $\mathrm{CdS} /$ wing, ${ }^{32}$ considering that the distance between adjacent lamellas $(100-200 \mathrm{~nm})$ is comparable to visible light wavelength. On the other hand, the normal brown scales without $\mathrm{PhC}$ color of the same butterfly (Euploea mulciber) could also act as scaffolds for nano-CdS assembly as presented in Fig. $6 \mathrm{~b}$ and c. The scale of $\mathrm{CdS} /$ wing in Fig. 6b lacks enough number of lamella periods (two), and the scale in Fig. 6c is missing the parallel lamella structures. Thus, both of them display normal yellow brown color. By applying the process to the Papilio paris butterfly wing, nano-CdS could precisely cover the PhC colored scales (Fig. 6d) and the dark brown scales (Fig. 6e) as well. According to the cross section of the composite colored scale (Fig. 6d), several parallel layers with thickness $100-150 \mathrm{~nm}$ also comparable to visible light wavelength are present beneath the patterned surface (inset in Fig. 6d). They should be considered as the origin of the $\mathrm{PhC}$ shining bluish green and yellowish green scales, as displayed between Fig. $6 \mathrm{~d}$ and e. Similar to the phenomenon of the male Euploea mulciber butterfly (Fig. 3), the PhC colors of the composites nano-CdS/Papilio paris are different from those of corresponding original wing and activated wing (not shown here). This may be due to the change of the parallel layers' $\mathrm{PhC}$ parameters, such as refractive index and lattice distance, and could imply the successful inheritance of the $\mathrm{PhC}$ features by nano-CdS coating. ${ }^{34}$ Moreover, Fig. 6e shows that the holes structure with sizes of several hundred nanometers is preserved in the nano-CdS/Papilio paris wing. Such structure could result in a darkening of the color, ${ }^{35}$ so that the composites exhibit a dark brown color. Therefore, various complex patterns, including two types of PhC structures, have been achieved on nano-CdS/wing scales, based on manipulating diverse scales from specific parts of a butterfly or from different butterfly species.

The above-mentioned samples and the sample corresponding to Fig. $7 \mathrm{a}$ and $\mathrm{b}$ were all derived from the typical procedure as described in the experimental section, displaying a homogeneous distribution of nano-CdS on the wing scaffolds. Furthermore, along with different procedure factors as listed in Table 1, there appear three types of nano-CdS small clusters, including the spherical (Fig. 7c and f), the worm-like (Fig. 7d, g and h) and the small island clusters (Fig. 7e, i and j). In particular, the samples in Fig. 7c-e were prepared by various activation procedures (Table 1), namely, the absence of the procedure, the shorter duration time, and the different activation agent, respectively. According to the foregoing FTIR analysis, the EDTA/DMF activation could provide additional active $\mathrm{COO}^{-}$sites for the subsequent loading process. Herein, the three kinds of nano-CdS
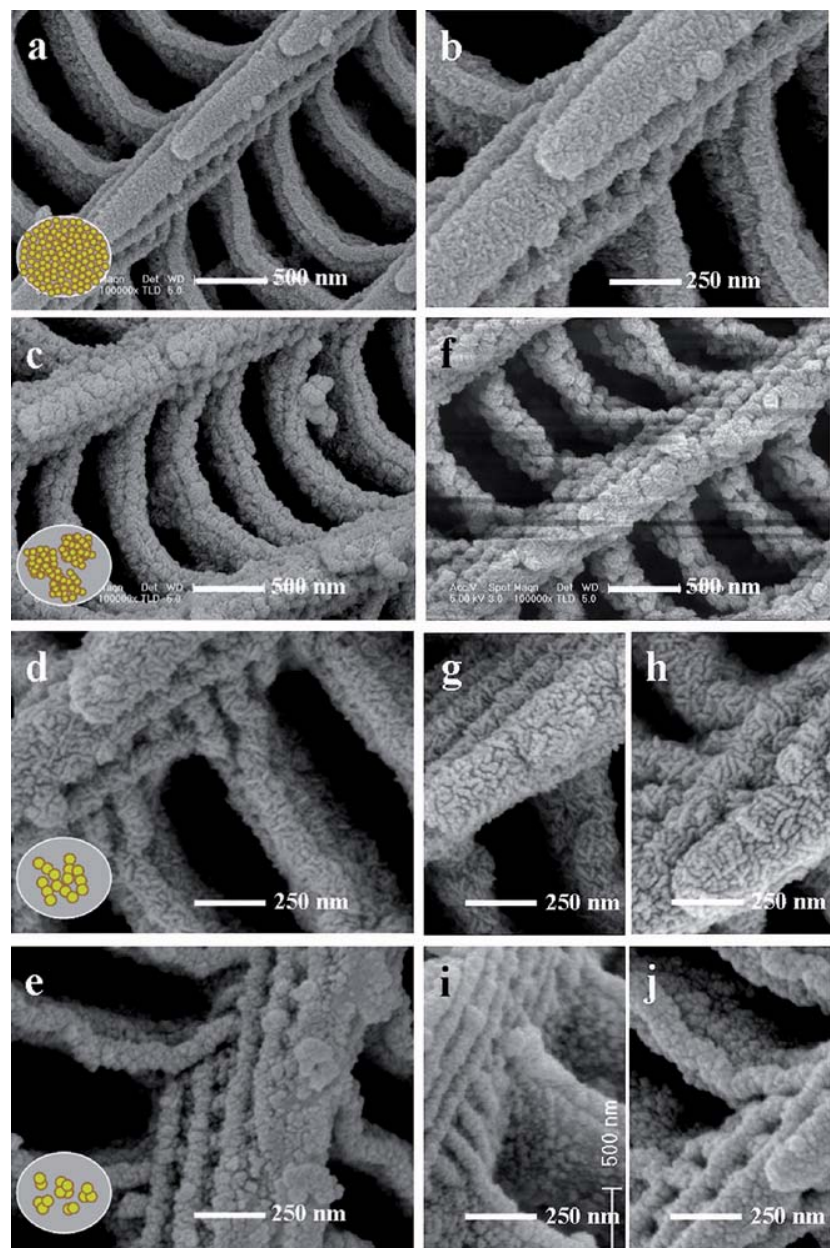

Fig. 7 FESEM images of nano-CdS/wings with $(a, b)$ homogeneous distribution of nano-CdS and $(\mathrm{c}-\mathrm{j})$ various patterns of nano-CdS small clusters that arecontrolled by procedure factors, which are (c,f) spherical, $(\mathrm{d}, \mathrm{g}, \mathrm{h})$ worm-like and $(\mathrm{e}, \mathrm{i}, \mathrm{j})$ small island. The cluster patterns are illustrated in the circle insets in (a, c-e), and the procedure factors are listed in Table 1. (The wing of male Euploea mulciber butterflies was used). 
cluster patterns on the final products (Fig. 7c-e) could be due to the different amounts of additional active sites, which demonstrates the importance of the activation process (see also ESI $\dagger$ ). In addition, the Step I and Step II processes should also be crucial to achieve the final patterns, according to Fig. $7 \mathrm{f}-\mathrm{h}$ and Fig. 7i-j, respectively. It seems that both insufficient CdS seeds (Fig. 7f and g) and the excess CdS seeds (Fig. 7h) on the wing scaffolds by Step I (Table 1) would draw down the aggregation of nano-CdS during Step II, and the various patterns of nano-CdS clusters in the final nanocomposites should correlate to the different amounts of $\mathrm{CdS}$ seeds. Moreover, the low $\mathrm{Cd}^{2+}$ concentration and the high $\mathrm{pH}$ value of the system for Step II (Table 1) could slow the heterogeneous nano-CdS deposition and finally result in small island patterns (Fig. $7 \mathrm{i}$ and j). Thus, the small cluster patterns of the primary nano-CdS on butterfly wing scaffolds could be controlled by the procedure factors.

\section{Conclusions}

In summary, butterfly wings could be activated via an EDTA/ DMF treatment to produce tunable amounts of $\mathrm{COO}^{-}$active sites on their structure surfaces, and then serve as the reactive scaffolds to direct the in situ formation and subsequent assembly of nano-CdS during a room-temperature soaking and a solvothermal procedure in succession. As-prepared nano-CdS are mainly cubic phase nanocrystallites with diameters of 6-7 nm, which precisely cover the wing scaffolds on both the exterior and the interior structures at the dimension from macro-scale down to nano-scale. The assembly patterns of nano-CdS in the final nano-CdS/wing scales are successfully controlled at two levels: one is the $\mathrm{PhC}$ structures $(>100 \mathrm{~nm})$ that can be varied by taking diverse scales from specific parts of a butterfly or from different butterfly species as the scaffolds, the other is the nano-CdS small clusters $(<100 \mathrm{~nm})$ that can be controlled by adjusting procedure factors. Therefore, butterfly wings have been demonstrated to be convenient substitutes for artificial $\mathrm{PhCs}$ in the assembly of nano-CdS. The obtained nano-CdS/wings are new $\mathrm{PhCs}$ with the reflection peak in the visible spectrum, which is essential in the control of light propagation. Furthermore, corresponding optical properties are supposed to be tunable by the nano-CdS/ wing assembly patterns. A related investigation is currently under way which should illuminate new valuable applications in light emitting and other PhCs fields.

\section{Acknowledgements}

Financial support from National Natural Science Foundation of China (Grant No. 50671065), the Major Fundamental Research Project of Shanghai Science and Technology Committee (Grant No. 07DJ14001, 09ZR1414700, 09520703400) and Sino-French Project of MOST of China (No.2009DFA52410) is gratefully acknowledged. The authors thank Leyan Zhuang, Zhirong Wang, and Chundong Wang from Shanghai Anti-counterfeiting Technical Products Testing \& Evaluation Center for reflection spectra measurement, Dr Jiajun Gu from State Key Lab of Metal Matrix Composites for XRD measurement, and SJTU Instrument Analysis Center for FESEM and FTIR measurements.

\section{Notes and references}

1 F. Fleischhaker and R. Zentel, Chem. Mater., 2005, 17, 1346.

2 A. Blanco, H. Miguez, F. Meseguer, C. Lopez, F. Lopez-Tejeira and J. Sanchez-Dehesa, Appl. Phys. Lett., 2001, 78, 3181.

3 A. Henglein, Chem. Rev., 1989, 89, 1861.

4 A. Blanco, C. López, R. Mayoral, H. Míguez, F. Meseguer, A. Mifsud and J. Herrero, Appl. Phys. Lett., 1998, 73, 1781; J. Zhang, N. Coombs and E. Kumacheva, J. Am. Chem. Soc., 2002, 124, 14512 .

5 K. Watanabe, T. Hoshino, K. Kanda, Y. Haruyama and S. Matsui, Jpn. J. Appl. Phys., 2005, 44, L 48; C. Lopez, Adv. Mater., 2003, 15, 1679.

6 P. Vukusic and J. R. Sambles, Nature, 2003, 424, 852.

7 M. Knez, M. Sumser, A. M. Bittner, C. Wege, H. Jeske, T. P. Martin and K. Kern, Adv. Funct. Mater., 2004, 14, 116; J. He and T. Kunitake, Chem. Mater., 2004, 16, 2656.

$8 \mathrm{H}$. Su, D. Zhang and Q. Dong, in Nanotechnology Research Developments, ed. R. Jiménez-Contreras, Nova Science Publishers, Inc., New York, USA, 2008, (ch. 9), pp. 315-378.

9 A. Singh, S. Hede and M. Sastry, Small, 2007, 3, 466.

10 R. Seshadri and F. C. Meldrum, Adv. Mater., 2000, 12, 1149.

11 W. Ogasawara, W. Shenton, S. A. Davis and S. Mann, Chem. Mater., 2000, 12, 2835.

12 H. Zhou, T. Fan, D. Zhang, Q. Guo and H. Ogawa, Chem. Mater., 2007, 19, 2144.

13 S. R. Hall, H. Bolger and S. Mann, Chem. Commun., 2003, 2784; Y. Wang, Z. Liu, B. Han, Y. Huang and G. Yang, Langmuir, 2005, 21, 10846.

14 D. Yang, L. Qi and J. Ma, Adv. Mater., 2002, 14, 1543; D. Yang, L. Qi and J. Ma, J. Mater. Chem., 2003, 13, 1119; Q. Dong, H. Su, D. Zhang and F. Zhang, Nanotechnology, 2006, 17, 3968.

15 Z. Miao, Z. Liu, B. Han, Y. Wang, Z. Sun and J. Zhang, J. Supercrit. Fluids, 2007, 42, 310.

16 Z. Liu, T. Fan, W. Zhang and D. Zhang, Microporous Mesoporous Mater., 2005, 85, 82 .

17 M. Kemell, V. Pore, M. Ritala, M. Leskelä and M. Lindén, J. Am. Chem. Soc., 2005, 127, 14178; J. Huang, N. Matsunaga, K. Shimanoe, N. Yamazoe and T. Kunitake, Chem. Mater., 2005, 17, 3513 .

18 J. Huang, X. Wang and Z. L. Wang, Nanotechnology, 2008, 19, 025602; R. J. Martín-Palma, C. G. Pantano and A. Lakhtakia, Nanotechnology, 2008, 19, 355704; N. L. Rosi, C. S. Thaxton and C. A. Mirkin, Angew. Chem., Int. Ed., 2004, 43, 5500.

19 R. O. Prum, T. Quinn and R. H. Torres, J. Exp. Biol., 2006, 209, 748.

20 J. Chen, Y. Lee, M. Tang and Y. Song, AIP Conf. Proc., 2007, 879, 1940.

21 G. Cook, P. L. Timms and C. Göltner-Spickermann, Angew. Chem., Int. Ed., 2003, 42, 557.

22 B. Li, J. Zhou, R. Zong, M. Fu, Y. Bai, L. Li and Q. Li, J. Am. Ceram. Soc., 2006, 89, 2298.

23 J. Huang, X. Wang and Z. L. Wang, Nano Lett., 2006, 6, 2325.

24 J. Silver, R. Withnall, T. G. Ireland, G. R. Fern and S. Zhang, Nanotechnology, 2008, 19, 095302.

25 W. Zhang, D. Zhang, T. Fan, J. Gu, J. Ding, H. Wang, Q. Guo and H. Ogawa, Chem. Mater., 2009, 21, 33.

26 E. Yablonovitch, Phys. Rev. Lett., 1987, 58, 2059; S. John, Phys. Rev. Lett., 1987, 58, 2486; C. López, Adv. Mater., 2003, 15, 1679.

27 J. S. Church, G. L. Corino and A. L. Woodhead, Biopolymers, 1997, 42, 7 .

28 P. Taddei, P. Monti, G. Freddi, T. Arai and M. Tsukada, J. Mol. Struct., 2003, 650, 105

29 S. C. Bhatia and N. Ravi, Biomacromolecules, 2000, 1, 413.

30 P. O'Brien and J. McAleese, J. Mater. Chem., 1998, 8, 2309.

31 S. Selvakumar, S. M. R. Kumar, G. P. Joseph, K. Rajarajan, J. Madhavan, S. A. Rajasekar and P. Sagayaraj, Mater. Chem. Phys., 2007, 103, 153.

32 S. Kinoshita and S. Yoshioka, ChemPhysChem, 2005, 6, 1442.

33 R. A. Potyrailo, H. Ghiradella, A. Vertiatchikh, K. Dovidenko, J. R. Cournoyer and E. Olson, Nat. Photonics, 2007, 1, 123.

34 P. Vukusic, R. Sambles, C. Lawrence and G. Wakely, Appl. Opt., 2001, 40, 1116.

35 P. Vukusic, J. R. Sambles and C. R. Lawrence, Proc. R. Soc. London, Ser. B, 2004, 271, S237. 